PHYSICAL REVIEW E 69, 059906(E) (2004)

\title{
Publisher's Note: Testing time symmetry in time series using data compression dictionaries [Phys. Rev. E 69, 056208 (2004)]
}

\author{
Matthew B. Kennel \\ (Received 24 May 2004; published 28 May 2004)
}

DOI: 10.1103/PhysRevE.69.059906

PACS number(s): 05.45.Tp, 99.10.Fg

This paper was published online on 14 May 2004 without a reference to materials stored in AIP's Electronic Physics Auxiliary Publication Service (EPAPS) archive. A citation to the EPAPS material (Ref. [22]) should appear at the end of the last sentence of the text prior to the Acknowledgments. Reference [22] has been added as of 20 May 2004 and appears in the printed version of the journal. 